\title{
Medico-social effectiveness of biological monitoring of iodine deficiency status (IDS) among women of reproductive age in Kazakhstan
}

\author{
Arailym Beisbekova ${ }^{1,2, A, D}$, Aizhan Raushanova ${ }^{2, C, E}$, Konrad Juszkiewicz ${ }^{3, F}$, Maikul Kainarbayeva ${ }^{1, B}$, \\ Ardak Chuyenbekova, ${ }^{1, B}$, Gulstan Khassenova ${ }^{1, B}$, Aigul Kozhakhmetova, ${ }^{1, B}$, Dinara Kenessary ${ }^{1, B}$ \\ ${ }^{1}$ Asfendiyarov Kazakh National Medical University, Department of Nutrition, Almaty, Kazakstan \\ ${ }^{2}$ Al-Farabi Kazakh National University, Almaty, Kazakhstan \\ ${ }^{3}$ Asfendiyarov Kazakh National Medical University, School of Public Health, Almaty, Kazakstan \\ A - Research concept and design, B - Collection and/or assembly of data, C - Data analysis and interpretation, D - \\ Writing the article, E - Critical revision of the article, F - Final approval of article
}

Beisbekova A, Raushanova A, Juszkiewicz K, Kainarbayeva M, Chuyenbekova A, Khassenova G, Kozhakhmetova A, Kenessary D. Medico-social
effectiveness of biological monitoring of iodine deficiency status (IDS) among women of reproductive age in Kazakhstan. Ann Agric Environ Med. 2019; 26(1): 73-77. doi: 10.26444/aaem/90718

\begin{abstract}
Introduction. lodine deficiency is one of the most important public health problems in the world. It mostly affects pregnant women and children. The lack of iodine leads to an increase in the numbers of perinatal mortality and mental retardation. Materials and method. In 2012-2014, a survey was carried out of 2,342 women, of whom 2284 were analyzed for salt to measure the content of iodine, and 2,242 women of reproductive age had their urine samples analyzed by the ceriumarsenite method based on the Sandell-Kolthoff reaction. Determination of the medical and social effectiveness of biological monitoring of IDS was carried out in 3 stages.

Results. The study revealed that in the eastern Kazakhstan region the relative risk (RR) of overall prevalence of iodine deficiency among women was 1.1 times higher (95\% ID: 0.35-3.61; Z statistic $=0.192$ ) among household respondents $(\leq 15 \mathrm{mkg} / \mathrm{kg})$. In the Pavlodar region, the RR of the prevalence of total iodine deficiency is 0.5 times higher in households where the salt was not sufficiently iodized. In the Zhambyl region the RR of the iodine deficiency prevalence was about twice as high due to insufficient iodized salt.

Conclusions. The introduction of biological monitoring of IDS among women, especially pregnant women, may positively affect the detection of the risk limits for the birth of infants with reduced mental abilities or other diseases during pregnancy, using timely targeted preventive measures to exclude factors that affect the spread of IDS.
\end{abstract}

\section{Key words}

iodine, iodine deficiency diseases, women of reproductive age

\section{INTRODUCTION}

Since the mid-1990s, IDS has been widely accepted as a public health problem, and many countries have included salt iodization and monitoring programmes as one of the country's domestic policies to improve the nutritional status of the population. Countries have gradually begun to depart from the definition of goitre among the population, as it was not accurate enough and did not fully reflect the population's iodine supply at the moment. Instead, attention shifted to monitoring salt production, quality, use in households and the level of iodine in urine, which is the main indicator characterizing the supply of iodine to the population of a particular region or country. This indicator is highly sensitive, responds quickly to changes in the level of iodine intake, and therefore is important not only for assessing the epidemiological situation, but also for monitoring programmes for the prevention of iodine deficiency disorders $[1,2,3]$.

Address for correspondence: Arailym Beisbekova, Asfendiyarov Kazakh National Medical University, Department of Nutrition, Almaty, Kazakstan, Klochkov st, 66. 080005 Almaty, Kazakhstan

e-mail: abeisbekova@gmail.com

Received: 13.02.2018; accepted: 02.05.2018; first published: 01.06.2018
Carrying-out biological monitoring of iodine status is a key step towards achieving complete elimination of iodine deficiency. Using a well-defined criterion for monitoring is the key to success towards the elimination of iodine deficiency.

The legislative confirmation of salt iodization and its monitoring in all countries is at different levels. According to available data from 40 European countries, only in 9 countries the level of iodization of edible salt in homeowners is about $90 \%$. According to the results of research, there are national programmes in only 17 European countries, and in the remaining 23 countries there are legislative norms, but which in turn do not obligate mandatory salt iodization [4]. Since 2007, 23 national studies have been conducted in Europe to determine the iodine status $[5,6,7,8,9,10]$.

In 2003, in Kazakhstan, taking into account the prevalence of iodine deficiency among indicator groups of population and low iodine provision, the Law of the Republic of Kazakhstan "On the Prevention of Iodine Deficiency Diseases" (IDD), approved by the Decree of the President of the Republic of Kazakhstan of 14.10.2003, No. 489-MHRK, вArticle 11 of this law states that all salt produced and sold in Kazakhstan for food purposes must be iodized, and the production, importation, sale of falsified salt is prohibited [11]. State 
interest was actively supported by salt producers to fight IDD and a targeted communication campaign had a huge impact on increasing iodized salt production and affected the quality of iodization $[12,13,14]$.

But with the passage of time, it became clear that an important point for the full operation of the law is the monitoring of iodine status. As the experience of many countries shows, the medical and social effectiveness of biological monitoring is very high. Biological monitoring of iodine deficiency status by the method of cross-sectional examination after a certain period of time, makes it possible to monitor the iodine status of the population, and react in a timely manner to the situation. The use of clearly defined criteria for monitoring is the key to success towards elimination of iodine deficiency.

\section{MATERIALS AND METHHOD}

In order to determine the background status of the iodine status of the population of Kazakhstan, the research data carried out within the framework of the State programme for the development of healthcare "Salamatty Kazakhstan" in 2011 by the Kazakh Academy of Nutrition and the Academy of Preventive Medicine [15]. A random sample of respondents among women of reproductive age from 14 regions of Kazakhstan and cities of the republic, significantly in Astana and Almaty, was carried out by a cluster method, taking into account the precinct principle in the areas of medical care for women of reproductive age. In 2011, 1,303 women of reproductive age were examined.

After a thorough analysis of the obtained results, using the random sample method, 9 regions of Kazakhstan were selected (Akmola, Aktobe, Almaty, East-Kazakhstan, Zhambyl, Mangistau, Pavlodar, North-Kazakhstan, SouthKazakhstan region) for a more detailed examination of women of reproductive age. In subsequent years, women were examined by a surveillance team and the results of the prevalence of ID, the quality and coverage of consumption of adequately iodized salt, and the results of a questionnaire survey about the problem of iodine deficiency were compared with background research grouped each year into 3 regions.

Every year, in the regional centre in each of the 3 regions of Kazakhstan, 8 groups were randomly selected: 2 clinics, and in every clinic 4 sites. In each site there were selected about 13-14 women of reproductive age. In 2012, in the Akmola, East Kazakhstan and South Kazakhstan regions 768 women of reproductive age were surveyed. In 2013, in Pavlodar, North-Kazakhstan and Aktobe regions, 757 women of reproductive age from the pool of sampled individuals were examined. In 2014, in the Almaty, Zhambyl and Mangistau regions 817 women of reproductive age were examined (Tab. 1).

Taking into account the possible refusal to participate and / or the absence of people included in the sample, the number of women chosen was increased by $12 \%$. In all years, field data collection studies were conducted in the summer-autumn period. The women were examined after receiving voluntary informed consent to participate in the study. Women were interviewed using a questionnaire in the language of their choice - Kazakh or Russian. Urine samples were collected from all the women and urinary excretion of iodine was analyzed to determine iodine status. Salt samples (10 grams)
Table 1. Indicators of sampling and the number of women surveyed'

\begin{tabular}{lcccc}
\hline \multirow{2}{*}{ Region/city } & \multicolumn{2}{c}{ No. of women } & \multicolumn{2}{c}{ No. } \\
\cline { 2 - 5 } & Expected & Actual & Cluster & Households in a cluster \\
\hline Kazakhstan & 1408 & 1303 & 64 & 22 \\
\hline in 2012 & 840 & 768 & 60 & 14 \\
\hline Akmola & 280 & 250 & 20 & 14 \\
\hline East-Kaz & 280 & 258 & 20 & 14 \\
\hline South-Kaz & 280 & 260 & 20 & 14 \\
\hline in 2013 & 780 & 757 & 60 & 13 \\
\hline Pavlodar & 260 & 256 & 20 & 13 \\
\hline North-Kaz & 260 & 250 & 20 & 13 \\
\hline Aktobe & 260 & 251 & 20 & $13-14$ \\
\hline in 2014 & 801 & 817 & 60 & $13-14$ \\
\hline Almaty & 267 & 264 & 20 & $13-14$ \\
\hline Zhambyl & 267 & 273 & 20 & $13-14$ \\
\hline Mangistau & 267 & 280 & 20 &
\end{tabular}

were also taken directly from households to determine in the laboratory the degree of iodination.

A study of the level of knowledge, skills, methods of prevention, eating habits of the women and the relationship of women of reproductive age to the problem of iodine deficiency, was conducted using the method of individual questioning according to a questionnaire. In general, the questionnaire included 37 questions, in Russian and Kazakh, respectively. Prior to each the submission of each questionnaire, the interviewers were obliged to receive verbal and written voluntary consent from the respondent to participate in this study. The questionnaires were preliminarily tested and approved by the local Ethical Commission (Protocol No. 06, 15.09.2010).

The concentration of iodine in a single urine sample was determined with the cerium-arsenite method on a flowthrough spectrophotometer Cecil CE 2041-2000 Series (England), which is based on the reaction of Sandell-Kolthoff, based on the catalytic action of iodine in the oxidationreduction reaction between cerium sulfate and arsenite [16]. With the help of this method, in the course of the study 2,322 of urine samples were analyzed of women of reproductive age - 753 in 2012, 752 in 2013 and 817 in 2014.

Statistical analysis of the iodine content of the biomaterial was performed using descriptive statistics. Calculated arithmetic mean (M), median (Me), standard deviation (SD), standard error of arithmetic mean (m), minimum (Min) and maximum (Max) values were used in the study. Statistically significant differences were determined using 95\% confidence intervals (CI). At the intersection of ID regions, the differences were not statistically significant at the alpha level error of 5\%. All calculations were performed using the statistical software package SPSS v. 17.0 (SPSS Inc, Chicago, IL,USA).

Salt samples were analyzed in the laboratory of the Kazakh Academy of Nutrition on the iodine content in salt by the method of iodometric titration. The method is based on titration of the liberated iodine with sodium thiosulphate. This method is set in the State standard of RK "Food Iodized Salt" Methods for determination of iodine and sodium thiosulfate, State standards of the Republic of Kazakhstan GOST R 51575 - 2003 [17]. This method was used to perform 
analysis of the quantitative content of iodine in edible salt in 2,284 samples - 764 samples in 2012 and 703 samples in 2013 and 817 samples in 2014 .

Evaluation of the medico-social efficiency of biological monitoring IDS among women of reproductive age and children was carried out according to the selected components conducting biological monitoring, which are important points of definition of medico-social efficiency:

- prevalence of Iodine Deficiency;

- adequacy of salt iodization;

- women's awareness of the problem of iodine deficiency.

At the first stage, the risk of giving birth to children with low mental abilities and the risk of birth with diseases (neonatal hypothyroidism, goiter, etc.) associated with iodine deficiency in the mother's body during pregnancy was calculated at selected points. From the number of newborns in each region, the number of newborn babies born from mothers with iodine deficiency during pregnancy was calculated.

At the second stage, unfavourable and favourable areas were identified for the prevalence of iodine deficiency, according to the determination of iodine concentration in urine.

In the third stage, the relative risk (RR) of the prevalence of the total iodine deficiency was calculated using the conjugation Table $(2 \times 2)$ in order to identify the cause of low iodine availability among surveyed women in unfavourable areas, due to inadequate iodine supply to the body through the consumption of inadequately iodized salt (Tab. 2).

The hazard ratio for the overall prevalence of iodine deficiency was defined according to the following formula:

$$
\mathrm{RR}=[\mathrm{a} /(\mathrm{a}+\mathrm{b})] /[\mathrm{c} /(\mathrm{c}+\mathrm{d})]
$$

Table 2. Conjunction table to identify relative risk

\begin{tabular}{lcc}
\hline \multirow{2}{*}{ Quality of salt } & \multicolumn{3}{c}{ Level of iodine } \\
\cline { 2 - 4 } & Insufficient level of iodine & Normal level of iodine \\
\hline Not enough iodized salt & A & B \\
\hline Adequately iodized salt & C & D \\
\hline
\end{tabular}

\section{RESULTS}

By medical efficiency in the presented case, is meant the health of pregnant women in the context of preventing diseases associated with iodine deficiency. Implementing biological monitoring in a monitored region with an adverse condition of iodine status on an indicator segments of the population (women of reproductive age), will be timely and targeted At prevention in these areas. This in turn will affect the iodine status of the entire population and reduce the number of newborns with reduced mental abilities and diseases associated with a lack of iodine intake (neonatal hypothyroidism, goiter, etc.).

Women of reproductive age and pregnant women are considered a sentinel group for determining iodine status. The social efficiency of biological monitoring is that the results obtained while conducting biological monitoring among women of reproductive age, including pregnant women, can be extrapolated to the entire population. During
Table 3. Social indicators for the years of the study, by regions

\begin{tabular}{llll}
\hline Year and region of study & No. of population & $\begin{array}{c}\text { Fertility rate (per } \\
1,000 \text { people) }\end{array}$ & No. of births
\end{tabular}

2012

\begin{tabular}{lccc}
\hline Akmola & 732,028 & 18.3 & 13,431 \\
\hline East-Kaz. & $1,394,165$ & 16.6 & 23,143 \\
\hline South-Kaz. & $2,650,188$ & 30.2 & 80,107 \\
\hline $\mathbf{2 0 1 3}$ & & & \\
\hline Pavlodar & 750,906 & 17.4 & 13,092 \\
\hline North-Kaz. & 577,627 & 14.8 & 8,550 \\
\hline Aktobe & 802,374 & 23.4 & 18,775 \\
\hline $\mathbf{2 0 1 4}$ & & & \\
\hline Almaty & $1,922,100$ & 26.3 & 50,551 \\
\hline Zhambyl & $1,098,700$ & 27.1 & 29,775 \\
\hline Mangistau & 606,900 & 32.2 & 19,542 \\
\hline
\end{tabular}

Note - data from the regional Departments of Statistics of the RK

pregnancy, due to active renal clearance, it is possible to identify a deficiency of iodine in the body, which is not always possible to detect before or after pregnancy.

To identify the risk of having children with iodine deficiency, the basic socio-economic indicators of the surveyed areas are required (Tab. 3).

From the number of surveyed pregnant women in the Akmola region, it was estimated that in 2012 an average of 19 - 460 children were at risk of having been born with reduced mental abilities, and with diseases associated with iodine deficiency (neonatal hypothyroidism, goiter, etc.). The greatest number of children born with this risk was observed in the East Kazakhstan region, from about 7,683-17,797, and in the the South Kazakhstan region in the range from 10,236-23,811 children. Data for 2013 in the Pavlodar region indicated from 3,498-7,055 children, in the North Kazakhstan region - from 31-626 children, and in the Aktobe region from 174-1629. According to the calculation data, this risk affected in 2014 in the Almaty region 2,744-9,460 children, in the Zhambyl region - 5,614-11,862 children, and the Mangistau region $1,444-3,780$ children.

As a result of the data obtained on the concentration of iodine in urine, as well as on the detected risks of the birth of children with low mental abilities and diseases associated with iodine deficiency, favourable and unfavourable areas were identified during the study period. Among unfavourable areas were included the South Kazakhstan region, East Kazakhstan region, and the Zhambyl and Pavlodar regions. Since, in these areas, along with the risk of giving birth to children with reduced intellectual abilities, deficits showed of a mild challenge to the average degree among the indicator groups (pregnant women). In the South Kazakhstan region, the overall prevalence of iodine deficiency amounted to 45.8\% (95\%ID:27;9-64.9), in the East Kazakhstan region up to $56.3 \%$ (95\%ID:33;2-76.9). At the same time, mild iodine deficiency among women prevailed. In Pavlodar and Zhambyl regions were recorded the highest number with a lack of iodine among pregnant women $64.7 \%$ (95\% ID: $41 ; 3-82.9)$ and $54.5 \%$ (95\%ID:34;6-73.1) respectively. The remaining 5 regions (Akmola, Aktobe, North Kazakhstan, Almaty and Mangistau regions) were classified as favourable regions in which were registered the number of cases with excessive iodine content among all surveyed categories. 
The results of research showed that the most significant factor in the psychological disturbances occurred in the East Kazakhstan, South Kazakhstan, Pavlodar and Zhambyl regions.

The greatest risk factor for the birth of children with mental disabilities was identified in the following regions: East Kazakhstan - relative risk (RR) of overall prevalence of iodine deficiency among women of reproductive age was 1.1 times higher (95\% ID: $0.35-3.61 ; Z$ statistic $=0.192$ ) among those respondents who had a salt with insufficient iodination found in households $(\leq 15 \mathrm{mkg} / \mathrm{kg})$. In the South Kazakhstan region, the relative risk (RR) of the prevalence of total iodine deficiency among women of reproductive age was 1.03 , but this indicator was statistically insignificant $\mathrm{p}=0.89$ (Tab. 4). In the Pavlodar region, the relative risk (RR) of the prevalence of total iodine deficiency was 0.5 times higher in households where the salt was not sufficiently iodized. And in the Zhambyl region, the relative risk (RR) of the prevalence of iodine deficiency due to consumption of insufficient iodized salt was twice as high.

Table 4. The relative risk of the prevalence of total iodine deficiency

\begin{tabular}{cccccc}
\hline $\begin{array}{c}\text { Area of } \\
\text { study }\end{array}$ & $\begin{array}{c}\text { Relative } \\
\text { risk (RR) }\end{array}$ & $\begin{array}{c}\text { 95\% Confidence } \\
\text { interval }(\mathrm{Cl})\end{array}$ & Z statistic & $\begin{array}{c}\text { Confidence } \\
\text { level }(\mathrm{p})\end{array}$ & NNT \\
\hline SKR & 1.03 & $0.7-1.7$ & 0.135 & 0.89 & 148 \\
\hline EKR & 1.09 & $0.4-2.6$ & 0.194 & 0.08 & 48 \\
\hline Pavlodar & 0.58 & $0.3-1.2$ & 1.501 & 0.13 & 5 \\
\hline Zhambyl & 2.01 & $0.4-9.1$ & 0.872 & 0.08 & 33 \\
\hline
\end{tabular}

\section{DISCUSSION}

Monitoring of the iodine status of the population is a key step towards achievement of the complete elimination of iodine deficiency. As the experience of many countries shows, the biological monitoring of iodine deficiency by cross-sectional studies after a certain period of time makes it possible to monitor the iodine status of the population, and to promptly react to the situation. After all, history shows that an uncontrolled attitude towards iodine, through dozens of years can be expressed with an increase in the number of births of children with various mental and physical abnormalities. Using of clearly defined criteria for monitoring is the key to success on the path to eliminating iodine deficiency. For example, since the 1960s, Finland has considered iodine deficiency to be a public health problem. Since then, in this country, studies have been conducted in a sporadic manner to determine the urinary excretion of iodine. In 2009, the National Institute for Health and Welfare reported on the need to monitor adequate salt iodization by determining through urinary excretion in individuals aged 24-75 years twice every 10 years $[18,19,20]$.

Since 1994, the Czech Republic has had a programme to control iodine deficiency. This programme involves the monitoring of salt iodization, the level of urine iodine content among the population and its awareness [21]. In Turkey, the programme on the prevention of iodine deficiency began in cooperation with UNICEF in 1994, with the aim of providing adequately iodized salt. The iodine deficiency is monitored every 5 years [22].
According to the WHO data for 2001, the median ioduria among the adult population of Norway aged 21-49.9 years was $85.0 \mathrm{mg} / \mathrm{l}$ [23]. The Government of Norway ordered the iodization of fodder salt for cows in 1950, chich after a period of time proved the effectiveness of universal salt iodization and its monitoring [24].

In the post-Soviet period (1999-2000), for the first time on the territory of the Republic of Kazakhstan, there was carried out an epidemiological study on iodine provision of the population, using modern indicators for assessing iodine deficiency [25]. More recent studies have shown that the frequency distribution of low concentrations of urinary iodine $(<100 \mu \mathrm{g} / \mathrm{l})$ among women of reproductive age in Kazakhstan have considerably decreased and amounted to $15.9 \%$. At the same time, the consumption of iodized salt in households in the Republic increased from $29 \%$ in 1999 to $83 \%$ in 2004, and to $91.4 \%$ in 2006 [26].

Taking into account all legislative and practical actions carried out in the Republic of Kazakhstan on the way forward in the fight against iodine deficiency, by agreement with international organizations (CDC, UNICEF, WHO, MI, IGN) with a network of sustainable elimination of iodine deficiency, in February 2010, the Republic of Kazakhstan was certified as a country that had achieved the elimination of iodine deficiency by the Universal Iodization of Salt (UIS). UIS should be supported by improving the legislation and system of biological monitoring, which should cover and monitor the use of iodized salt in industrial foods and in households to supply the population with iodine.

Iodine deficiency disorders affect mainly the vulnerable part of the population - women of reproductive age and children. Therefore, it is necessary to consolidate and place on a long-term, priority basis, periodic monitoring of quality control of the UIS, as well as iodine security of the population, aimed at further elimination of Iodine Deficiency Disorders.

\section{CONCLUSIONS}

It must be bornein mind that the deviations in mental development due to insufficient intake of iodine can only be prevented by ensuring an adequate intake of iodine in the mother's body during pregnancy. With the introduction of periodic biological monitoring of iodine deficiency conditions, it is possible to monitor and identify regions with a problem of iodine intake, and take timely and immediate measures to ensure adequate iodine nutrition by the sectors of the population At risk.

The presented analysis confirmed that the body's supply of iodine is directly dependent on the adequate intake of iodine through the consumption of iodized salt. Women who consumed quality iodized salt, had excretion rates of iodine in the urine within the normal range, which indicates the complete provision of the body with iodine. Thus, the introduction of periodic biological monitoring of iodine deficiency status among women of reproductive age, especially pregnant women, will affect the detection of the risk limits for the birth of infants with reduced mental abilities or other diseases associated with an inadequate intake of iodine during pregnancy and through timely targeted preventive measures exclude factors that affect the spread of iodine deficiency. Preventive measures in the fight against the prevalence of iodine deficiency / excess are an 
important tool on the way to eliminating diseases associated with the inadequacy of iodine intake into the body.

The introduction of the system of biological monitoring of iodine among the population allows estimation of the population's consumption of iodine at the population level, confirming the presence or absence of iodine deficiency, iodine adequacy or excess of iodine, assessing its severity, determining the effectiveness of the activities conducted and assessing the adequacy of iodine adjustment, not only at country level, but also at regional level.

The introduction of the biological monitoring system and its data can be used as an information source for international cooperation in the field of fighting micronutrient deficiency, and will contribute to the international assessment of the situation of IDD at the regional level.

\section{Acknowledgements}

The study was carried out within the framework of the social order of the Ministry of Health of the RK "Organization of constant biological monitoring for the provision of indicator groups of the population with iodine, iron, folic acid and vitamin $\mathrm{A}$ in all regions of the Republic and Astana and Almaty cities". We express our gratitude to Academicians Sharmanov Toregeldy Sharmanovich, Professor Tazhibayev Shamil Saginovich, Professor Ospanova Feruza Erkebekovna, and to Frits van der Haar, the international expert on iodine.

\section{REFERENCES}

1. Ospanova FE. Influence of a complex of preventive measures on the prevalence of IDD and the supply of iodine. Hyg Epidemiol Immunobiol. 2010; 45(3): 12-15

2. Morreale de Escobar G, Obregon MJ, Escobar del Rey F. Role of thyroid hormone during early brain development. Eur J Endocrinol. 2004; 151(Suppl 3): 25-37.

3. Delange F. The disorders induced by iodine deficiency. Thyroid. 1994; 4(1): 107-128.

4. Aldo Pinchera. Progress against IDD in Europe. IDD Newsletter. 2010; 36(2): P.66-75.

5. Andersson M, Karumbunathan V, Zimmermann MB. Global iodine status in 2011 and trends over the past decade. J Nutrition. 2012; 142(4): 744-750.

6. Zimmermann MB. Iodine deficiency and excess in children: worldwide status in 2013. Endocrine Practice. 2013; 19(5): 839-846.

7. Delange F, Bürgi H. Iodine deficiency disorders in Europe. Bull World Health Organization. 1989; 67(3): 317-325.

8. Andersson M, Karumbunathan V, Zimmermann MB. Global iodine status in 2011 and trends over the past decade. J Nutr 2012;142: 744-750.
9. Zimmermann MB, Andersson M. Update of iodine status worldwide. Curr Opin Endocrinol Diabetes Obes. 2012; 19: 382-387.

10. Delange F. Iodine deficiency in Europe and its consequences: an update. Eur J Nucl Med Mol Imaging 2002; 29: 404-416.

11. Law of the Republic of Kazakhstan "On the Prevention of Iodine Deficiency Diseases"adopted by the decree of the President of the Republic of Kazakhstan from 14 October 2003,N 489, Article 11.

12. Beibekova AK, Ospanova FE. Iodine - the most important factor in reproductive health. Materials of the Republican Scientific and Practical Conference with International Participation "Healthy Nutrition as the Basis of a Healthy Way of Life" dedicated to the $20^{\text {th }}$ anniversary of Independence of Kazakhstan "Actual Issues of Healthy Lifestyle Formation, Disease Prevention and Health Promotion”. 2011; Almaty, Kazakhstan.

13. Beisbekova A, Ospanova F, Tolysbayeva Zh, Nurgabylova A, Tazhibayev Sh, Sharmanov TSh, Grjibovskii A. Evaluation of iodine situation on the background of USI in Kazakhstan. Eur J Epidemiol. 2013; 28: 284.

14. Beisbekova A, Tolysbayeva Zh, Ospanova F, Tazhibayev Sh, Sharmanov T. Current iodine intake among children and women of reproductive age in Kazakhstan. Book of Abstracts, $6^{\text {th }}$ International Symposium on Recent Advances in Food Analysis. 2013; Prague, Chech Republic.

15. The state program of development of public health services of the Republic of Kazakhstan "Salamatty Kazakhstan” on 2011-2015 years from 29 November 2010 № 1113.

16. Pino S, Fang SL, Braverman LE. Ammonium Persulfate: a safe alternative oxidizing reagent for measuring urinary iodine. Clin Chem. 1996; 42: 239-243.

17. Methods of determination of iodine and sodium thiosulfate, State standards of the Republic of Kazakhstan GOST R 51575 - 2003.

18. Lamberg BA. Endemic goiter in Finland and changes during 30 years of iodine prophylaxis. Endocrinol Exp. 1986; 20(1): 35-47.

19. WHO, UNICEF. Iodine deficiency in Europe: A continuing public health problem // World Health Organization. Geneva, 2007. - P.85-95.

20. WHO. WHO Global Database on Iodine Deficiency. The database on iodine deficiency includes data by country on goitre prevalence and/ or urinary iodine concentration. World Health Organization. Finland, 2009:11-20.

21. Website of the International Council for the Control of Iodine Deficiency Disorders. ICCIDD global network. http://www.iccidd. org.(access:2014.06.26)

22. Aldo Pinchera. Progress against IDD in Europe. IDD Newsletter. 2010;36(2):66-75

23. WHO. WHO Global Database on Iodine Deficiency. The database on iodine deficiency includes data by country on goitre prevalence and/ or urinary iodine concentration. World Health Organization. Norway, 2006. P.22-30.

24. Dahl L, Johansson L, Julshamn K, Meltzer HM. The iodine content of Norwegian foods and diets. Pub Health Nutr. 2004; 7: 569-576.

25. Kazakh Academy of Nutrition, UNICEF An assessment of the household use and adequacy of iodized salt in the Republic of Kazakhstan. Almaty, 2004.285p.

26. Agency of the Republic of Kazakhstan on Statistics, UNICEF, USAID, UNFPA, UN Resident Coordinator. Kazakhstan: Monitoring the situation of children and women. Multiple Indicator Cluster Survey 2006. Astana, 2007. P. 158. 